\title{
Respuesta a la carta al editor respecto al artículo "El consentimiento informado: recomendaciones para su documentación"
}

Miguel Ángel Celis, Julio Sotelo, José Halabe, Oscar Arrieta, Rubén Burgos, Carlos Campillo, Manuel De la Llata, Judith Domínguez, Sergio Islas, Luis Jasso-Gutiérrez, Alberto Lifshitz, Mucio Moreno, Ricardo Plancarte-Sánchez, Alejandro Reyes, Guillermo Ruiz-Argüelles, Antonio Soda y Emma Verástegui

Comité de Ética y Transparencia en la Relación Médico-Industria, Academia Nacional de Medicina, Ciudad de México, México

El Comité de Ética y Transparencia en la Relación Médico-Industria (CETREMI) elaboró la propuesta "EI consentimiento informado. Recomendaciones para su documentación", con propósito de llamar la atención de la comunidad médica sobre conductas y prácticas en las instituciones de salud tanto públicas como privadas, en las cuales se da poco espacio a la participación de los pacientes en la toma de decisiones. Se percibe este fenómeno como origen de conflictos y quejas entre los usuarios, producto de una pobre comunicación.

Como se señala en el artículo, "el personal de salud debe actuar con ética y transparencia siguiendo los principios de beneficencia y no maleficencia" al proporcionar información, pero no deben estar por encima del principio de autonomía en las decisiones del paciente. Por ello, las recomendaciones del CETREMI son claras y precisas, como un llamado a la reflexión y a la autocrítica que propicie mejores relaciones médico-paciente y paciente-institución, que también redundarán en mejores prácticas y en la calidad integral de la atención.

\section{Bibliografía}

1. Celis MÁ, Halabe J, Arrieta O, Burgos R, Campillo C, De la Llata M, et al. El consentimiento informado: recomendaciones para su documentación. Gac Med Mex. 2018;154:716-718. DOI: 10.24875/GMM.18004339. 